\title{
An analysis of English network teaching mode in Higher Vocational Colleges in the Internet Era
}

\author{
Zhu Liyan \\ Hunan Railway Professional Technology College, Zhuzhou, 412001, Hunan
}

Key words: English Network Classroom Teaching Reform in the network era

\begin{abstract}
. the network brings about great changes and challenges to the classroom teaching, it enriches the teaching resources, creating English language environment. The form of the novel and lively multimedia teaching can stimulate students' learning interest and enthusiasm, to make up for the defects of the traditional English teaching, which can greatly improve the teaching efficiency and teaching quality. At the same time. Network teaching to English teachers presents new challenges, that is to renew the conception, improve the professional quality and technical education, improve teaching efficiency and effectiveness.
\end{abstract}

With the increasing popularity of computer applications, and the rapid progress of information technology, people are not out of the house to be able to know the world. Multimedia into the classroom, to the English classroom teaching has brought great changes and challenges.

A multimedia teaching network, becomes the trend of the development of English teaching, information technology and other characteristics of the times is gradually infiltrated into the field of education, has changed the traditional relationship between teachers and students. The "Teacher centered" classroom teaching mode no longer dominate, the application of multimedia teaching equipment for English teaching has opened up a great new world, "the student as the center, as the main project of the new teaching mode of network is becoming more and more attention. This model emphasizes individuality and team cooperation consciousness in the teaching, teachers are more to the director or instructor to guide students, organization, inspiration, evaluation of the whole teaching process. Students can benefit Using the campus network or the Internet for individual learning, participate in group activities, through the network media to complete the study or discussion topic. In addition, this kind of teaching mode has changed the traditional teachers and students sit in classrooms across the dogmatic single teaching mode, mode of communication between teachers and students become diverse. At the same time, the network provides a free space for students to express their ideas and put forward their own problems, teachers can transfer images through multimedia, sound and other information, individualized education, truly individualized teaching methods. Multimedia teaching to overcome the drawbacks of traditional teaching of the new teaching for us The way, make the abstract, boring learning content into the image, interesting, visual and audible dynamic content, it has become the development trend of English teaching.

To increase the capacity of English classroom teaching, enrich the teaching resources of English teaching and other subjects teaching, it is a pure language discipline. The content of the traditional blackboard teaching can hold too little, not conducive to the students and teachers, and the use of multimedia equipment to make every teacher can design a number of board. A small disk bearing capacity is far from a blackboard and can.

The network has enriched the content of classroom teaching, to expand their horizons, make up the deficiency of traditional teaching methods, reasonably resolve the difficulty of knowledge, focus 
on teaching, optimize classroom teaching, effectively mobilize the initiative of students, to provide the best education for teaching English courses. This means, not only enhance the students learning English the interest in and explain some of the content of the abstract text, can also provide a visual image of the scene for students, to facilitate students' comprehension, memory, correct pronunciation errors.

On the cultivation of students' listening, say, read, writing ability can not be ignored, be the cure China students "dumb English" this common medicine. Using the powerful functions of the multimedia computer, students can not only set up the virtual computer and dialogue, but also according to EEG evaluation (including phonetics, morphology, syntax even the idioms) correct their mistakes, which to improve the students' expression ability is very useful. Computer assisted language teaching as a modern teaching technology, more and more English teachers attention. Both teachers and students from the website to find innumerable various Knowledge, or for classroom teaching, or homework. Get the resources than to find the traditional library to be convenient, more quickly. Although the "information explosion" will inevitably be lost, but some of the best search engine for teachers and students to the pilot, to help them find the information they need as much as possible.

Three, the creation of English language environment to create a harmonious and efficient classroom teaching atmosphere, more initiative of students, enable students to actively participate in, mouth and mind in active development. Multimedia provides extremely favorable material conditions for English teaching, it not only retains the characteristics of the computer, can show simple text and digital characters such as teaching information, audio-visual equipment and has the perfect presentation of image and sound, but also the output of animation, video, images and sounds, very easy to do the teaching of information map, text, voice and multidimensional education. The dissemination of information, enhance the information authenticity and performance the multimedia. In English teaching has an extraordinary performance.

The main difficulty in English teaching before students exposed to it very few opportunities, almost only in the classroom, and often only in the classroom teaching mode and teaching knowledge, learn to memorize knowledge, grammar points. This teaching of the English class is not angry, most of the students from the experience of no pleasure from fatigue and steering weariness. Multimedia teaching can configure some animation, increase the interest of beginners, lively and vivid picture can also make the students to remember, increase students memorizing ability to knowledge.

With the further development of the reform of English teaching, situational language teaching has been paid more and more attention. In the teaching, can conveniently show the perceptual material with CAI, to create the best situation, so as to obtain the best teaching effect.

However, we must pay attention to the rationality of the application, otherwise it will lead to a less consequence.

Four, network teaching teachers need to become excellent navigator computer is teaching assistant, learning a good helper. Assisted learning system posed by the use of multimedia technology in foreign language teaching, can be fast paced, high capacity of training students. The teachers should only do some guidance work, you can put the teaching work be perfect, students can also use the computer network to find out information on the accumulation of knowledge and update, make students more effectively improve the learning efficiency. In the network teaching, although the enthusiasm of teaching students as a teaching subject, the initiative can be fully play the leading role of teachers, but did not Is ignored. This is mainly because the network information uneven in quality, affect inexperienced students often vulnerable to bad information. In addition, the 
network information is extremely rich, in order to avoid the students lost their freedom to explore the network reduce the time required for the teachers' guidance is necessary. This requires that teachers must have strong ability to obtain information and recognition ability, to help and guidance, the pilot's identity to guide students to use the network correctly, to ensure that the network teaching of the normal. Because of the rapid development of computer technology, intelligent teaching system can be used as a computer teacher to replace teachers in the heavy task of teaching, making teaching Teachers can have energy, have time to participate in the student individual or group learning activities, the academic advisory role to diagnose students' learning and academic job needs, help students choose a plan to meet the needs, and indicates the development direction of students' academic program.

Five, network teaching of English teachers to put forward new challenges in the network society, rapid renewal of knowledge, teachers must continue to learn to adapt to social development. With the advent of information age, network technology, multimedia technology brings a new revolution in the field of higher education, access to information, information processing the dissemination of information, the ability to become teachers. Twenty-first Century

The teacher is faced with the deep reform: update the concept of education, improve education technology, to explore new teaching mode, improve teaching efficiency and effectiveness. The existing problems are: on the one hand, with rich teaching experience and professional knowledge of the teachers in the computer and network technology knowledge and operation level of slightly less than the other. On the one hand, although the young teachers in computer operation slightly, but does not have much experience in teaching English, and this talent overall is still scarce. This requires teachers to walk out from the traditional teaching mode, make full use of modern information technology and the integration to the practice of teaching to adapt As an education department, it should provide effective measures and approaches to the realization of teachers' new abilities, so as to ensure the realization of teachers' ability and the improvement of information quality.

The correct application of multimedia technology in English Teaching of Higher Vocational Education under the network environment in strengthen the information technology education for teachers and students According to the students level of network technology uneven in quality situation, vocational colleges should strengthen the education of English teachers, improve their professional skills and occupation quality of teachers, encourage teachers to use their spare time to participate actively in various studies, through the modern education technology training, and constantly improve the teachers use the teaching software and multimedia network technology level. At the same time, it is also to the students of computer education and training, and guide students to actively use the Internet to learn English, improve the efficiency of English learning, broaden the knowledge.

Improve the quality of multimedia courseware making

High quality multimedia courseware not only to be able to stimulate students' interest, but also to follow the students' cognitive laws, carefully designed teaching activities. In the production of courseware interface to follow the principles of simplicity and artistry, to be able to arouse the attention of students, stimulate students' curiosity and thirst for knowledge. For the focus of the content, through special effects, such as changing the font color, wavy lines, and other ways to highlight the word art. In the collection of courseware material, make full use of the rich content, the form of a variety of network resources.

Correctly using the multimedia courseware

rational use of multimedia courseware to assist teaching. Like some cultural background heavy 
text can use the multimedia courseware to present the background knowledge of the text. Such as "HealthyEating" class, the text is mainly about the health and diet related knowledge. This can make use of multimedia courseware, showing the different Western habits in diet to students by showing pictures, video clips, and then show the Pyramid healthy diet pattern, and then guide the students to discuss and draw the final conclusion. In this way, students can not only complete the classroom learning, but also broaden the knowledge. Although multimedia teaching has obvious advantages, but not all of the English class are suitable for the use of multimedia teaching means.

give full play to the student's main body position. In multimedia teaching, higher vocational English teachers must fully realize that multimedia teaching is only an auxiliary teaching method, which serves the teaching activities, and the subject of classroom teaching activities is still a student. Teachers should get rid of the traditional roles and adapt to the new changes. Therefore, in the multimedia teaching, teachers in addition to focus on the important and difficult knowledge, but also left more than half of the time to the students. As in "LoveandMarriage" in the first lesson, according to the Convention, by a student do riddles, stories, songs, tongue twisters and other forms of oral report, to discuss the issues raised by the students. Then enter the text learning, teachers to slide show "LoveandMarriage" in the title of the small poem, to attract the attention of students, leading to the "wedding" the theme. Then on the basis of preview, in the form of pictures and music will be the background knowledge vivid, vividly displayed. Then on the text of the heavy and difficult to explain the knowledge through the projection, interspersed with questions. Then the students divided into a number of groups, on the "Areyoufororagainstlobola" debate. In the end, the two groups of the debate were summed up by the teacher. With the help of multimedia technology, the teaching content is presented in all directions and multi angles. It is helpful for students to grasp the knowledge.

In short, the introduction of multimedia technology into College English classroom under the network environment, the purpose is to better serve the teaching activities, so as to enhance the teaching effect. Compared with the traditional teaching model, multimedia teaching has obvious advantages. The teachers should make full use of this advantage to assist teaching, so that all aspects of classroom teaching are clearly purpose. This requires that college English teachers should be correct, reasonable and making use of multimedia courseware, which should accord with the cognitive law of students, teachers and their characteristics should be combined. If the multimedia courseware is too fancy, in order to apply modern teaching methods and use, is bound to be overwhelming", In the multimedia teaching form than content, appear the tendency of entertainment. Therefore, teachers should learn to make multimedia courseware, applying multimedia courseware, truly serve the students increase knowledge, enhance service to the students' English ability.

\section{Acknowledgements}

2014 annual fund of Ministry of education occupation college foreign language teaching steering committee "research and practice of network English classroom teaching mode in Higher Vocational Colleges network foreign language teaching research based on the Internet Era" (project number: GZGZ5414-110)

\section{References}

[1] Li Yan. The diversified teaching mode and evaluation mode of Higher Vocational English under the network environment [J]. science and technology information, 2001 (1) 
[2] How tall the modern education information technology and modern foreign language teaching $\mathrm{J}$. Chinese audio-visual education, 2002 (1)

[3] Ke peace. Multimedia resource library construction and application of network teaching J. Modern educational technology, 2002 (1)

[4] Wang Shouren, Zhao documents under the network environment. The English education J. Foreign language studies, 2002 (5) 